\title{
Ciespal: una huella indeleble en la conformación de las teorías latinoamericanas de comunicación
}

Ciespal: an indelible mark on the conformation of Latin American communication theories

Ciespal: uma marca indelével na conformação das teorias latinoamericanas de comunicação

Juan Camilo MOLINA

Universidad UTE - Ciespal / camimolinv@gmail.com

Chasqui. Revista Latinoamericana de Comunicación

$N .^{o} 141$, agosto - noviembre 2019 (Sección Informe, pp. 365 - 376)

ISSN 1390-1079 / e-ISSN 1390-924X

Ecuador: CIESPAL

Recibido: 24-07-2018 / Aprobado: 29-11-2019 


\title{
Resumen
}

Este artículo revisa el surgimiento y consolidación de las teorías de la comunicación de América Latina y El Caribe (ALC) y su relación con la influencia del Centro Internacional de Estudios Superiores en Comunicación para América Latina (Ciespal). Como tal, es parte de una investigación más amplia, que revisa 179 documentos para reconocer el pensamiento regional y presenta sus primeros resultados. Se concentra en el período de finales de la década de los sesenta y los noventa, aunque abarca hasta inicios del siglo XXI. Revisa la génesis y desarrollo de la escuela latinoamericana, en cuatro esquemas (histórico (Esteinou), geográfico (Pineda), escuelas (Mattelart \& Mattelart; Alcázar \& Álvarez; Kaplún) y definición de campo (Martín Barbero; León) con el horizonte de comprensión de la "institucionalización de la teoría latinoamericana" (Marques de Melo, Orozco, León, Moyano) y la hipótesis de que su núcleo originario se da con la creación de Ciespal.

Palabras clave: teorías de comunicación, Ciespal, escuela de comunicación latinoamericana, internacionalización, institucionalización

\begin{abstract}
This article reviews the emergence and consolidation of communication theories in Latin America and the Caribbean (LAC) and its relationship with the influence of the International Center for Higher Studies in Communication for Latin America (Ciespal). It is a part of a larger research, which reviews 179 documents, to recognize regional thinking and presents its first results. It focuses on the period of the late sixties and nineties, although it covers until the beginning of the 21st century. Review the beginnings and development of the Latin American school, in four approaches (historical (Esteinou), geographic (Pineda), schools (Mattelart \& Mattelart, Alcázar \& Álvarez, Kaplún) and field's definition (Martín Barbero, León) with the assumption of the "institutionalization of Latin American theory" (Marques de Melo, Orozco, León, Moyano) and the hypothesis that its original core occurs with the creation of Ciespal.
\end{abstract}

Keywords: communication theories, Ciespal, Latin American communication school, internationalization, institutionalization

\section{Resumo}

Este artigo analisa o surgimento e a consolidação das teorias da comunicação da América Latina e do Caribe (ALC) e sua relação com a influência do Centro Internacional de Estudos Superiores em Comunicação para a América Latina (Ciespal).Como tal, faz parte de uma pesquisa maior, que analisa 179 documentos, para reconhecer o pensamento regional e apresentar seus primeiros resultados. Concentra-se no período do final dos anos sessenta e noventa, embora abranja até o início do século XXI. Revise a gênese e o desenvolvimento da escola latinoamericana, em quatro esquemas (histórico (Esteinou), geográfico (Pineda), escolas (Mattelart \& Mattelart, Alcázar \& Álvarez, Kaplún) e definição de campo 
(Martín Barbero, León) com o horizonte de compreensão da "institucionalização da teoria latino-americana" (Marques de Melo, Orozco, León, Moyano) e a hipótese de que seu núcleo original ocorra com a criação do Ciespal.

Palavras chave: teorias da comunicação, Ciespal, escola latino-americana de comunicação, internacionalização, institucionalização 
Agradecimiento especial al equipo investigador de apoyo ${ }^{1}$

Me percaté de que sólo quiero investigar lo que otorgue esperanza. Debemos investigar no solamente lo que permite denunciar, sino aquello que permite transformar, aunque sea en pequeña medida. Siempre recurro a una teoría brasileña no escrita, la teoría de las brechas, según la cual todo muro, por más macizo que parezca, presenta siempre una grieta que alguien puede profundizar para derrumbarlo.

Jesús Martín Barbero (en Moura, 20og)

\section{Introducción}

El presente documento es un acercamiento a las teorías y escuelas latinoamericanas de la comunicación a partir de su interacción con el Centro Internacional de Estudios Superiores en Comunicación para América Latina (Ciespal). Sin embargo, se precisa una doble aclaración de los límites de su alcance: su intención no es describir la evolución de la teoría latinoamericana de comunicación en todo su contenido, ni tampoco pretende ser una semblanza o descripción histórica de Ciespal, para lo cual se indica la bibliografía especializada. Su objetivo es adentrarse en los puntos que relacionan el pensamiento comunicacional de América Latina y El Caribe (ALC) con la identidad e influencia de Ciespal. Como tal, es parte de una investigación más amplia para reconocer el pensamiento propio y, desde allí, vincular las líneas editoriales y de investigación con las problemáticas y redes regionales. Este informe presenta los primeros resultados y se concentra en el periodo de finales de la década de los sesenta y los noventa, aunque abarca hasta inicios del siglo XXI, revisando la génesis y desarrollo tanto de Ciespal como de la escuela latinoamericana, con el horizonte de comprensión de la "institucionalización de la teoría latinoamericana” (Marques de Melo, Orozco, León) y la hipótesis de que su núcleo originario se da con la creación de Ciespal.

La estructura de su presentación sigue cuatro puntos:

Primero, inicia con un marco teórico-interpretativo de la comunicación en ALC que parte de las formas precolombinas (Beltrán, 2008; Ferreira, 2000) seguida por cuatroesquemas posibles para comprenderlateoríalatinoamericana de comunicación moderna: la revisión cronológica en tres fases, desde inicios del S. XX hasta finales de la década de los 80 (Esteinou, 1984); la escuelas

1 Agradecemos a Michelle Abata, pasante de investigación de la Escuela de periodismo de la Universidad UTE, quien apoyó como investigadora principal en la revisión de la metodología y la sistematización de la información. Agradecemos los aportes en la construcción y clasificación de la base de datos, brindado por las pasantes de investigación: Katherine Altamarino y Carla Campos de la Universidad Politécnica Salesiana de Quito. De igual forma, se señala que las opiniones son de responsabilidad del autor. 
clásicas de comunicación y su impacto desde ALC, que agrega la reflexión hasta inicios del S. XXI (Mattelart, 2005; Escudero \& Álvarez, 2015; Kaplún, 2013); el seguimiento en torno a los núcleos temáticos y la institucionalización de la teoría latinoamericana de comunicación (Martín Barbero, 2014; Marques de Melo, 1998, 2000, 2012; Fuentes, 2016); y la regionalización con tres escuelas: norteamericana, europea y latinoamericana (Pineda de Alcázar, 2001). Se cierra con los debates sobre el campo profesional y la agenda contemporánea de investigación.

Segundo, se explica la construcción de la metodología a partir de experiencias previas de las tendencias de investigación en ALC (Álvarez \& Castillo, 2015; González, Rodríguez, \& Aguaded, 2017), la construcción de un corpus bibliográfico sobre la relación entre Ciespal y cada fase-núcleo-contexto señalado, considerando específicamente la institucionalización de la teoría latinoamericana y su rol en la propia producción (Chasqui).

Tercero, se presentan las principales categorías de análisis y hallazgos generados en esta parte de la investigación.

Finalmente se dan unas conclusiones y sugerencias, que no buscan dar un cierre al debate, sino abrir el intercambio de ideas para el fortalecimiento de la comunicación y su impulso institucional en la construcción de las democracias y ciudadanías.

\section{1- Propuestas para un marco interpretativo de la teoría latinoamericana de comunicación en su relación con Ciespal}

Como punto de partida, se encuentra el ingente esfuerzo de Luis Ramiro Beltrán (Beltrán et al, 2008), quien ahonda en los estudios sobre la comunicación en ALC más allá del hito del surgimiento de la imprenta (1539 en México) y que se "remonta a catorce mil años, a las primeras comunidades que dejaron muestras de organización social y de formas de comunicación” (Gumucio, 2010), lo que implica un cambio en la concepción del proceso civilizatorio de la cultura impresa europea a otro en el cual se tiene "en el centro a la comunidad y a la organización social como hechos comunicacionales” (Idem). Beltrán señala que su interés parte de los congresos anuales de los pueblos indígenas en Ecuador, desde el fundante I Congreso (1976). Esto se profundizó durante su estancia en Quito entre 1981 y 1984, la investigación en Ciespal y el intercambio con el trabajo del ecuatoriano Wilson Hallo sobre los sellos parlantes ${ }^{2}$ y las

2 El trabajo estaba asociado al grupo Piru, fue liderado por el pintor catalán Moisés Villelia quien investigó los sellos cilíndricos de culturas precolombinas ecuatorianas", analizando "su estructura compositiva desde una perspectiva estética del diseño". Lo interesante de este hecho fue el descubrimiento de su nivel de complejidad pues "en la duplicación de los diseños bajo un patrón específico de esas imágenes, con la intención de encontrar un "mensaje" mayor, haciendo evidente un manejo de la abstracción y estilización de las imágenes". Esto significó entonces "la posibilidad de que su objetivo era utilizarlos como un medio de comunicación simbólico, lo que implicaba encontrar el sistema de decodificación". La investigación quedó en el punto en el que la conoció Beltrán. El grupo Piru publicó bajo el sello editorial 
posibilidades de contar con un alfabeto y sistemas de comunicación trasladadas a tejidos y otras expresiones precolombinas. Esta perspectiva se acrecentará con los aportes de Ferreira (2000) en su relectura de las investigaciones sobre la fonética y escritura maya de Knorosov ${ }^{3}$ aplicadas a la narrativa de las culturas amerindias; de Gargurevich sobre la semántica y lenguaje simbólico incaico; de la investigación historiográfica de Rodríguez Oliva quien comparó, principalmente, los archivos sobre comunicación precolombina de la Casa de las Américas y de Ciespal; y, finalmente, de los aportes de Miller, Pinto y Torrico en el proyecto del Ameribcom (Amerindia-Iberia-Comunicación) para comprender las formas propias de comunicación (Beltrán et al, 2008), las posibilidades de una publicidad oral y grafológica en los usos de tecnologías precolombinas, así como en el reconocimiento de su culturas.

Con este precedente, puede revisarse la comunicación latinoamericana en su vertiente moderna, que data del S. XX (Orozco, 1997, Moyano, 2016). Para ello, se sigue a Esteinou (1984), quien vincula este pensamiento con la presencia de Ciespal y propone una periodización que permite comprender "la producción de la conciencia científica sobre los fenómenos de la comunicación en América Latina" a partir de obras y autores clave ${ }^{4}$. Esta se da en tres momentos importantes, relacionados entre el surgimiento de los medios y la elaboración de conocimientos sobre sus formas de producción:

- primero, "la fase clásico-humanista (1900-1945)" en la que se daba un sentido positivista a la comunicación, como un hecho dado, sin mayor análisis, salvo algunos aportes de su discurso literario y casos sobre el impacto de la propaganda. En este contexto, la comunicación se enfocaba desde el conductismo, la posibilidad y eficacia para persuadir, con la

de la Fundación Hallo, Bajo un mismo sol, sus hallazgos en el texto: Síntesis histórica de la comunicación y el periodismo en el Ecuador, cuyo prólogo es de Luis Ramiro Beltrán. Más información en: http://tacuara. org/fundacion-hallo/.

3 Una presentación de la obra de Knorosov, considerado por Ferreira como el primer teórico de la comunicación latinoamericana, y las dificultades para su reconocimiento en medio de la guerra fría en: http://www.bibvirtual.ucb.edu.bo:8000/beltran/index.php?option=com_content\&view=article\&id=4 2\%3Aleonardo-ferreira-y-luis-ramiro-beltran-investigan-la-escritura-precolombina\&catid=1\%3Alocal\&Itemid=50\&showall $=1$

4 Esteinou (1984) realiza su documento en la conmemoración de los 25 años de Ciespal y señala como textos fundamentales para la comprensión de la comunicación los textos de: 1) Prieto Castillo, D. (1977). Elementos para una Teoría de la Comunicación (1977), publicado conjuntamente con el ILCE; 2) de Moragas Spa, M. (1970). El trabajo teórico y las alternativas a las "Mass Media". En: Alternativas Populares a las Comunicaciones de Masas, Vidal, J. Madrid: Ed. Centro de Investigaciones Sociológicas. 3) Villagrán, C. (1977). Los Problemas de la Ideología y la Ciencia de la Comunicación. En: Revista Mexicana de Ciencias Políticas y Sociales. No. 86-87. México: UNAM. pp. 75-84. 4). El texto editado por Ciespal de Martín Barbero, J. (1978). Comunicación Masiva Discurso y Poder. Colección Intiyán No. 7. Quito: Ciespal. 5) Piccini, M. (1978). La Investigación Sobre Medios de Comunicación en América Latina. Simpósium Nacional de la Comunicación: La Experiencia de EUA. Universidad Iberoamericana. Adicionalmente, Esteinou explica la estructuración latinoamericanista en: Un Solo Mundo. Voces Múltiples: Comunicación e Información en Nuestro Tiempo. México: Ed. Fondo de Cultura Económica. pp. 383-385; y David Amorío, J. (1977). El Papel de la Enseñanza y de la Investigación en Comunicaciones en América Latina. En: Actas de III Encuentro Nacional de Investigadores de la Comunicación. Instituto de Investigaciones de la Comunicación, Universidad Central de Venezuela. 
aplicación de horizontes interpretativos pragmáticos que buscaban "mejorar la publicidad, organizar campañas electorales, conocer las debilidades de la opinión pública, aumentar la venta de periódicos, superar la imagen institucional del estado, etc.” (Esteinou, 1984), así como una enseñanza humanista, elitista, con menor énfasis en las habilidades prácticas y lejana al contexto del desarrollo propio;

- segundo, "la fase científico-técnica (1945-1969)", que preludia la expansión de la globalización económica y cultural y exigía el rápido desarrollo de la ciencia de la comunicación para asegurar el funcionamiento adecuado del sistema social" (Esteinou, 1984). El factor innovador de esta época es la aplicación de herramientas cuantitativas para explicar la influencia de la comunicación (medios masivos) en el comportamiento, los gérmenes de la educomunicación y apenas una postura crítica respecto de los emisores que cedía espacio frente al funcionalismo cultural (contexto en el que surge Ciespal);

- tercero, "la fase crítico reflexiva (1965-1984)", en la que se posiciona la autoconcepción de la comunicación latinoamericana y la necesidad de un enfoque cercano al cuestionamiento sobre los modelos de desarrollo (centro-periferia, dependencia, emancipación) y que vinculó a la comunicación con la realidad social y los abordajes interdisciplinarios en diversos frentes (relaciones de poder nacional-internacional de los medios, génesis discursiva, "la apertura a la comunicación alternativa popular, el impacto de las nuevas tecnologías de comunicación, la instauración de un nuevo orden mundial de la información").

De manera similar, algunos autores revisan las tendencias clásicas de la comunicación, como los aportes de Mattelart \& Mattelart $(2003)^{5}$ y Chaparro

5 Los Mattelart (1995) dividen su obra de Historia de las teorías de la comunicación en siete apartados: 1) el organismo social, que se acerca a la sociología, las ciencias sociales y la comunicación, desde su epistemología y desarrollo de los métodos; 2) los empirismos del nuevo mundo, reflexiona sobre el surgimiento de los estudios de comunicación de la primera década del S. XX en los EUA, el contexto de la Escuela de Chicago y la Mass Comunication Research, el funcionalismo, con los debates sobre el poder de influencia de los medios, los métodos cuantitativos, el surgimiento de la etnografía, la comunicación para el desarrollo y las visiones de la emancipación vs alineación en los mensajes y medios; 3) la teoría de la información, ubicada en los años 40, podría comprenderse como neopositivista con el encuadre de una comunicación matemática, cercana a metodologías tales como la criptografía, coste de emisión de mensajes, isomorfismo, sistémico y con una visión lineal y lógica de la comunicación; 4) industria cultural, ideología y poder, quizás el más extenso y profundo en debate. Parte de una vertiente de la teoría crítica y la racionalidad técnica, se cuestiona al funcionalismo en su visión de los medios como mecanismos decisivos de regulación social (reproducción de valores) y reflexionan sobre las consecuencias de este uso a partir de su imposición simbólica y reutilizan el concepto de ideología. Luego, analiza la vertiente estructuralista, donde retoma los debates de la lingüística, semiología, la antropología estructural, el análisis de los dispositivos y aparatos de control y aplica estas reflexiones a la sociedad de espectáculo, el estudio del discurso de los medios de comunicación y el debate sobre la adecuada comprensión de los medios realizado entre Enzensberger y Baudrillard. Más adelante, en la vertiente de estudios culturales, su tradición educativa, literaria, antihegemónica, la resistencia comunitaria y los estudios de recepción; 5) economía política, como reflexión sobre "el desequilibrio de los flujos de información y de produc- 
Escudero (2015), que se pueden seguir en la conjunción de diez escuelas principales y su impacto en la producción de la comunicación latinoamericana (Castillo \& Álvarez, 2015): la escuela de Chicago, el funcionalismo de la Mass communication research, la teoría de la información, la teoría crítica (en las lecturas de la primera y segunda escuela de Frankfurt), el estructuralismo, los estudios culturales, los estudios de movimientos intersubjetivos, la Escuela Latinoamericana de la Comunicación (ELACOM), los estudios sobre recepción y los estudios de la sociedad información ${ }^{6}$ (los dos últimos irán más allá de las fases de Esteinou, con un análisis hasta inicios del S. XXI).

Resulta interesante comparar esta lectura con el aporte de Kaplún (2013) sobre las "tradiciones fundacionales", tres de las cuales ya se han señalado: funcionalista, crítica, culturalista, junto a la corriente alternativista (más abierta e interdiciplinar), y una quinta, emergente, de estudios críticos del modelo (posde-colonial e intercultural), cuya importancia consiste en ser "base instituyente de modos de mirar, pensar y hacer la comunicación en América Latina” (2013, p. 68). En ese sentido, Pineda de Alcázar (2001) también considera el balance de los aportes de las teorías clásicas de la comunicación y su génesis tri-regional ${ }^{7}$ con la escuela norteamericana (conductista-funcionalista-neopositivista), la escuela europea (crítica- psicoanalítica- neomarxista- opinión pública- estructuralistaestudios culturales) y los estudios con perspectiva crítica latinoamericana de la comunicación en cinco áreas: comunicación alternativa, los estudios sobre la dependencia cultural, la democratización de las comunicaciones y el nuevo orden informativo internacional, los estudios sobre mediaciones simbólicas y las teorías sobre las apropiaciones críticas.

tos culturales entre los países situados a uno y otro lado de la línea de demarcación del «desarrollo»", con un análisis de la tensión entre políticas gubernamentales de democratización cultural y las lógicas comerciales, en sus líneas de dependencia cultural, integración vs intercambio desigual, dominación cultural, la generación del informe MacBride sobre los problemas globales de la comunicación; 6) el regreso de lo cotidiano, aborda escuelas que reaccionan frente al estructuralismo-funcionalismo y aboga por una recuperación de la intersubjetividad en las ciencias humanas y la autonomía de las audiencias respecto a los medios, las etnometodologías, el interaccionismo simbólico, el giro lingüístico y la acción comunicativa, para adentrarse en la etnografía de las audiencias, los usos y gratificaciones; 7) la influencia de la comunicación, que revierte la ecuación sociedad-comunicación hacia una sociedad definida en términos de comunicación, red, digitalización. Llama la atención que la propuesta latinoamericana no aparece como una escuela, aunque un artículo d Maldonado (2010) y Duarte (2010) del especial de la Revista Chasqui 110 (2010) abordan la cuestión. Castellanos Cerda (2009), amplía el análisis de la obra.

6 El artículo de Castillo \& Álvarez (2015) es un ejercicio con base en la revisión bibliográfica de la producción comunicológica y su recopilación en bases académicas para tomar a estas escuelas como las variables e indicadores teóricos y perspectivas del campo de la comunicación.

7 Para la autora se podrían ver del siguiente modo las escuelas: la escuela norteamericana (con Laswell) como pionera y fundamento de la matriz teórica neopositivista cambios sobre el receptor, con autores como Herscovici, Álvarez, Lozano, Mattelart, López Veroni, De Oliveira; la teoría de la fijación de la agenda pública (Cohen, Comb y Shaw) que acentúan el papel de los medios en la configuración política y cultural (donde se añade McLuhan y para la región Martín Barbero); la Escuela Europea, con énfasis en el pensamiento crítico y que acude a las tesis neomarxistas y del psicoanálisis (Frankfurt), con los aportes de Mattelart, Saperas; el estructuralismo francés del S. XX que acude al análisis del medio al mensaje (Levy Strauss); la Escuela Inglesa o de los Estudios Culturales, que propone retomar los elementos culturales del marxismo clásico (Hall, Birgmihan); y la escuela crítica latinoamericana. 
Sin embargo, más allá del esquematismo de estas clasificaciones, Martín Barbero (2014) sugiere su comprensión a partir del contexto de la construcción de los campos de la comunicación en ALC, estableciendo tres hitos importantes en los últimos cincuenta años:

- el primero, se centra en los orígenes de los planteamientos, ligado a teorías propias latinoamericanas como la dependencia-liberación, el debate sobre el subdesarrollo y que plantea una comunicación para la emancipación de Freire (en su enfoque pragmático de comunicación-acción y su programa pedagógico) (Martín Barbero, 2014), que influye fuertemente en la educomunicación y comunicación comunitaria. Se resalta asimismo el inicio de la investigación crítica en Venezuela (Pasquali, Gómez), México y de las radios comunitarias (Colombia y Bolivia). Al sur, en Chile y Argentina se indaga desde la semiología (Verón), la teoría de la dependencia y en torno a la institucionalización de los medios masivos y su lectura crítica e ideológica (Mattelart, Smuchler, seguida por Mastrini, Becerra, Bolaño (Kaplún, 2013) y Follari);

- el segundo, con la reflexión sobre lo popular y la comunicación, el discurso, los usos sociales, las audiencias, recepción y consumo, se destaca la escuela de estudios culturales latinoamericana y los aportes de Martín-Barbero, García Canclini, Orozco, Rincón, Vasallo, Fuenzalida y Jacks, quienes junto a otros comunicólogos desarrollaron teorías sobre el consumo, la capacidad crítica de las audiencias, las mediaciones, así como diversas teorías críticas que evolucionaron al reconocimiento de los públicos y las nuevas formas de comunicación política (Duarte, 2001, pp. 25 - 26);

- el tercero, se refiere a los estudios actuales de la sociedad de la información y la "globalización y mutación tecnocultural de la comunicación" (Barbero, 2014. p. 31). Autores como Ortiz y Santos contextualizan los abordajes del sistema-mundo dentro del debate ya existente en ALC sobre la centralidad de la periferia y la de interculturalidad.

Aquí también se puede incluir al carácter institucional de la teoría de la comunicación latinoamericana (Marques de Melo, Fuentes, Moyano, Orozco) que se produce gracias a la conformación y dinámica de centros especializados. El origen de este movimiento está en CIESPAL que en 1959 inicia la investigación y capacitación para la especialización profesional, dándole un sentido más crítico al trabajo y una pluralidad de actividades (Marques de Melo, 1988, p. 6). A esta institución se suman la Asociación Latinoamericana de Investigadores de Comunicación (Alaic) creada en 1978, con una serie de investigaciones enfocadas al desarrollo y la convergencia de necesidades "de comunicación" entre los diversos espacios regionales: Andino, Centroamérica y el Cono Sur. Para 1981, se incorpora la Federación Latinoamericana de Facultades de Comunicación Social (Felafacs) con el propósito de renovar a fondo la formación profesional/ 
universitaria de los comunicadores para la creación de posgrados que buscaban especializar el campo docente (Barbero, 2014, pp. 24-25). Para Fuentes (2016), estas iniciativas se enmarcan en "la intercomunicación organizada y sostenida entre actores individuales e institucionales en una región tan grande como América Latina (...) y la importancia que puede atribuirse a los procesos de institucionalización de los nexos académicos interpersonales, interinstitucionales e internacionales". Se destaca el Seminario Sobre investigación de la Comunicación en América Latina, adelantado por Ciespal en $1973^{8}$, que junto a la Primera Conferencia Regional de Unesco en Políticas de Comunicación (Beltrán, Díaz Bordenave, Pinto, Reyes) servirían de base para aportes al Informe MacBride (1978) y del Nuevo Orden Mundial (1980).

De forma particular, el rol activo de la Escuela Latinoamericana de Comunicación (ELACOM) se incrementa desde mediados del S.XX en el reconocimiento e identificación a la comunidad regional de investigadores en comunicación (León, 2008) y su revisión histórico-crítica (Torrico, 2000; Beltrán, 1974).

Martín Barbero indica un apartado especial para Marques de Melo, como uno de las figuras más relevantes para su comprensión ${ }^{9}$. Este autor propone algunas características centrales de la ELACOM en desde los ochenta hasta la primera década del S. XXI (en León, 2017), gracias a la internacionalización de las discusiones existentes sobre las tendencias de la investigación de la comunicación y una revisión crítica de sus procesos. Siguiendo esta línea, la ELACOM se desarrolla gracias al "combate al aislacionismo" (por la interacción continua al interior de Latinoamérica) y la superación del "síndrome del colonizado" "renuncia a la tarea de examinar críticamente el referencial teórico acumulado", reproducción "sin discusión los cuadros cronológicos esbozados en los países que lideran la producción académica mundial "y la "estigmatización a nuestras vanguardias intelectuales pues viene produciendo un comportamiento insólito de amnesia histórica" (Marques de Melo, 2004: 15, en León, 2017).

Quizás la mejor definición de esta forma latinoamericana es la enunciada por Marques de Melo, como un saber práctico en su triple dimensión: autóctono, mestizo y popular ${ }^{10}$, como:

8 Este seminario significó el primer esfuerzo por un análisis del estado de la investigación latinoamericana sobre comunicación.

9 Por la extensión de su obra aquí no se revisan a los numerosos artículos y textos que tiene en referencia a la escuela latinoamericana, aunque se retoman algunas de sus tesis. De todas maneras, sus libros: $G \hat{e}-$ nese do pensamento comunicacional latino-americano: o protagonismo das instituições pioneiras- CIESPAL, ICINFORM, ININCO (2000) y Pensamiento comunicacional latinoamericano. Entre el saber y el poder (2009) son fundamentales.

10 Dentro de los puntos de debate que menciona Marqués de Melo se ven ligadas tres líneas de acción: "el trabajo sobre la naturaleza del proceso de la comunicación; la autonomía teórica y el fomento a la crítica metodológica; el rescate del conocimiento empírico, en su triple dimensión: autóctono, mestizo y popular. Estableciendo un punto de partida en donde las investigaciones estén centradas en estimular el comportamiento de los emisores y su efecto. Continuando con la elaboración de una propuesta en donde se centren en recurrir a estrategias investigativas para mejorar la calidad de los productos permitiendo en un futuro un dialogo abierto y equilibrado, finalizando con una meta o un punto de llegada en el cual se rescate". Ver: León, 2017, pp. 20-22. 
El hibridismo teórico y la superposición metodológica, que se caracteriza por los cruces de tradiciones europeas, herencias meso-suramericanas (pre y pos colombinas), costumbres africanas, innovaciones de modernas matrices norteamericanas, además de muchas contribuciones introducidas por los distintos grupos étnicos que navegaron por los océanos durante las recientes sagas migratorias internacionales (Marques de Melo en León, 2017, p.19).

\section{Esquemas y propuestas para la interpretación de la teoría de la comunicación y su influencia en América Latina}

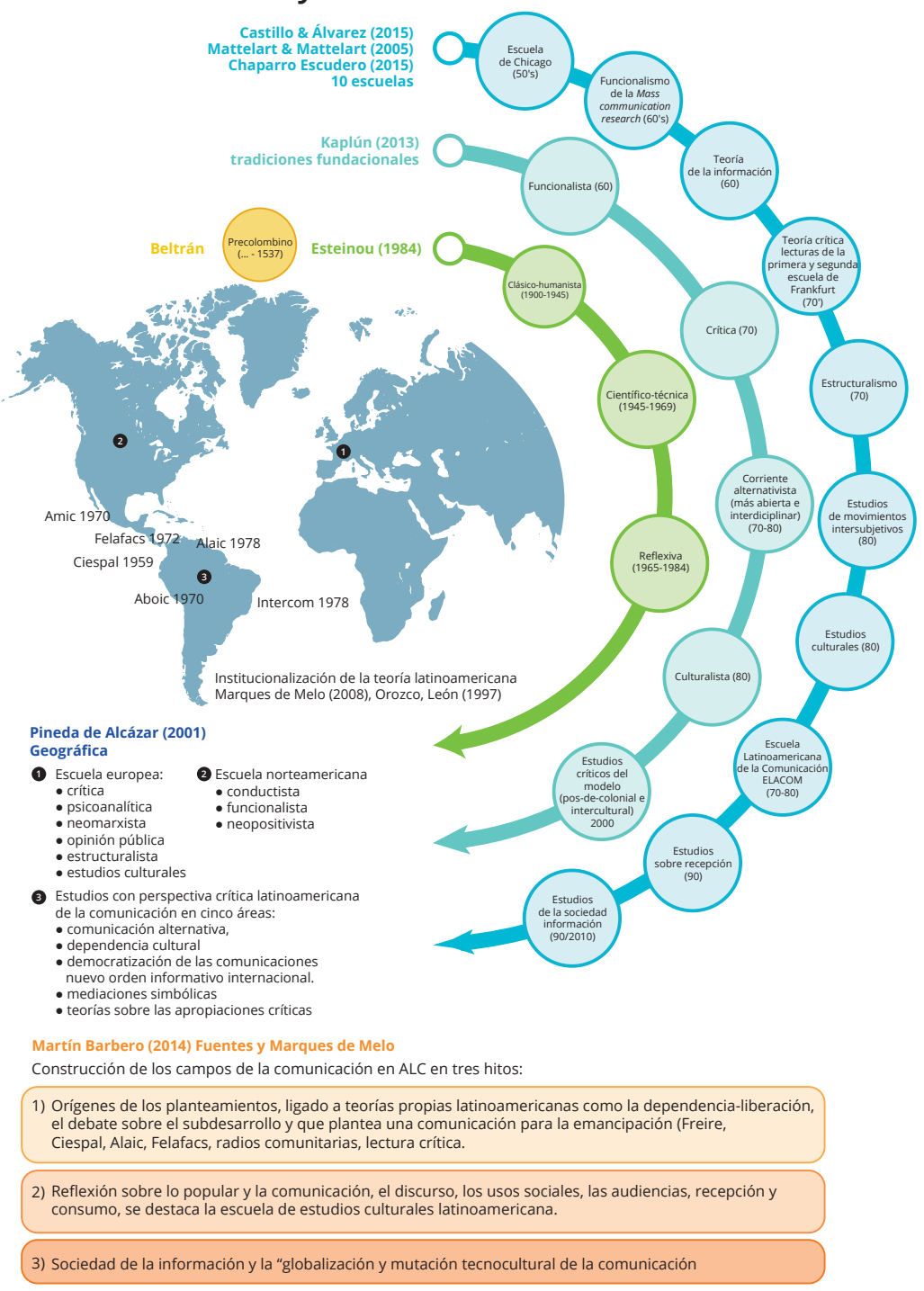

Elaboración: Camilo Molina. Diseño: Diego Acevedo 
Más adelante, se dan reflexiones sobre el impacto de las propuestas críticoinnovadoras dentro del campo de la comunicación (Álvarez \& Castillo, 2015). Esta discusión se consolida en el ámbito del ejercicio profesional y se liga con nuevos enfoques dentro de la sociedad de la información y del conocimiento, partiendo desde el uso de las TIC y las nuevas formas de investigación y comunidades académicas (Mellado, 2010), las cuales desdibujaron ciertas fronteras para permitir un intercambio continuo al interior de los países de la región y que no había sido posible con anterioridad (Beltrán, 2007).

Para otras posturas, de igual modo, se requiere subsanar vacíos, por ejemplo en la tradición sobre la conceptualización del campo del "comunicador" y "periodista", con búsquedas propias en relación el surgimiento del campo profesional, el estatuto epistemológico, la tensión entre pragmatismo y los contenidos de formación (Belletini \& Ordoñez, 2013; Roveda, 2006). Asimismo, se requiere una ecología (MacLuhan) de las teorías de la comunicación que permita expresar en los fenómenos culturales sus dimensiones e implicaciones (Roncallo, Uribe \& Goyeneche, 2016) ${ }^{11}$. Como señalan Gutiérrez \& Cramer (2019), el paso de la institucionalización y producción de los medios a una revisión de la vida cotidiana se presenta como un desafío en la actualidad para que la historia de la comunicación supere "la mirada unidireccional de la transmisión y los meros análisis del código y del mensaje hacia una entrada compleja desde la dinámica de la cultura" (1014).

\section{Propuesta metodológica}

A partir de los esquemas analizados, se revisó la bibliografía especializada que permitiera un seguimiento del rol de Ciespal en el contexto de la comunicación de ALC.

Para hacerlo, se acudió a los análisis metodológicos de la producción bibliográfica de comunicación en ALC y la forma de construcción de su aparato crítico. Se observó que los estudios dan una lectura cronológica de las investigaciones latinoamericanas en bases de datos especializadas (González, Romero \& Aguaded, 2017; Castillo, Almasa \& Álvarez) así como del ejercicio sobre las prácticas teórico-metodológicas institucionales (Moyano, 2018). Estas formulaciones coinciden con la dificultad planteada en el primer apartado (Mattelart, Beltrán, Martín Barbero, Lopes de Vasallo, 2012; Maldonado, 2015) acerca de la construcción temática sobre el campo de estudio pues "no se pueden encontrar homogeneidades de líneas de pensamiento sobre la disciplina que logren la creación de una única línea epistemológica” (González, Romero \& Aguaded, 2017).

11 La síntesis de León (2001) es una amplia panorámica de la situación y desafío de la escuela latinoamericana de comunicación desde los elementos de análisis del modelo de comunicación mismo: 1). Producción y distribución de mensajes; 2). Contenido del mensaje y, 3). Recepción del mensaje. 
Adicionalmente, dada la recurrencia de artículos de Chasqui que reflexionaban sobre Ciespalyla escuela latinoamericana, se realizó una búsqueda en su archivo con el objeto de ampliar dos cosas: primero, la participación que los autores centrales identificados en la revisión teórica aportaron a la enunciación de la escuela latinoamericana en Ciespal; y, segundo, los artículos y ediciones que reflexionaran sobre el rol de Ciespal en esta construcción.

De este modo, se diseñó un corpus analítico en dos niveles así:

- documentos que indagan sobre Ciespal y su impacto en la comunicación de ALC: Fuentes (2014, 2016), y sus reflexiones sobre la producción de comunicación en ALC y la agenda de investigación. Luego la clasificación de las escuelas de comunicación latinoamericana de Marques de Melo (en León (2017), seguida por sus textos sistemáticos (1987, 2009; Marques de Melo \& Gobbi, 2009); así como las de Prieto (1985; 2009) y Kaplún (1985) desde el ámbito de la educación y comunicación popular en ALC y de Bolaño (2012) desde la economía política. Se incluyen también documentos que revisan específicamente la acción de Ciespal en la comunicación de ALC: Barreto (1991), Hurtado (2005), Mellardo (2010), León (2012), Checa (2016); Moyano (2016, 2018);

- para el caso de Chasqui, Revista Latinoamericana, se tuvieron presentes todos los artículos, tanto de su Primera (21) como Segunda (140) épocas, con un total de 161 números. Para la selección final se analizaron las temáticas de los artículos, las clasificaciones de sus conceptos y las alusiones sobre Ciespal. Se destacaron los Números 11, 13, 32, 67, 86, 87, 88, 100 y 107, correspondientes a las revisiones sobre Ciespal. En ellos participaron autores como Prieto, Mattelart, Kaplún, Beltrán, Marqués de Melo, Martín Barbero, Pasquali, García Canclini, Fuentes Navarro y Fuenzalida, de quienes se hizo una selección completa de todos sus aportes.

De los 178 artículos revisados, se contó finalmente con 97 (ver referencias bibliográficas 1 y 2 ).

\section{Ciespal y la investigación sobre comunicación en América Latina y el Caribe: Discusión y hallazgos}

El origen del Centro Internacional de Estudios Superiores de Comunicación para América Latina (Ciespal) es fruto de un movimiento de enseñanza del periodismo con varios precedentes (Mesa, 1984): la actividad de Unesco para generar centros regionales de comunicación en 1955, la primera reunión de expertos en periodismo (13-04-1956) y el primer el seminario sobre comunicación (1958) que coincidió con la apertura del centro de estudios de comunicación en Estrasburgo por parte de UNESCO (15-10-1958). Gracias a las gestiones de la Universidad Central del Ecuador y del gobierno ecuatoriano, se propone a Quito para albergar un centro latinoamericano similar al francés, iniciativa que 
se presenta en junio de 1958 durante la Segunda Conferencia de Comisiones Nacionales de Unesco. Luego de varios acuerdos ${ }^{12}$, el 8 de octubre de 1959 se inaugura la sede de Ciespal, como una institución que permitiera comprender y difundir el pensamiento propio de ALC en el campo profesional de periodistas y comunicadores, proporcionando herramientas para su práctica, la indagación sobre nuevos conocimientos teóricos y metodológicos y su vinculación con centros académicos.

Ahora bien, el contexto en el que nace Ciespal se ubica entre las escuelas de ciencias de la información, la sociología del desarrollo, el funcionalismo y los debates sobre el mediocentrismo (Moyano, 2016; Orozco, 1997; Gutiérrez \& Cramer, 2019). Para Orozco (1997), Ciespal tuvo un matiz particular por la red de becarios, así como por la influencia de las escuelas de Mass Communication Research norteamericana (coincidiendo con Esteinou, 1984) y la Sciences de L'Information europea y que, de acuerdo a Mattelart \& Mattelart (1995, en Moyano, 2016), retoma las preocupaciones de la Escuela de Chicago sobre la representación, los efectos de los medios (la prensa, radio y la televisión) y el crecimiento de las ciudades.

Esta incorporación en el denominado "paradigma funcionalista", llevó a Ciespal a tomar "un tipo de orientación teórica y metodología identificada con el difusionismo y presente en las investigaciones volcadas al estudio de la difusión de innovaciones en el contexto rural, bajo el tutelaje teórico de Rogers, Lasswell, Lazarsfeld, Schramm y Kaiser" (Moyano, 2016, p.12). Su producción se focaliza junto a proyectos regionales de desarrollo (rural), aunque ya se daba una reflexión crítica desde los gremios de periodistas y comunicadores sociales para que, además de la educación y la salud, la información se considere como un derecho (Steinsleger, 2004, p.17).

En marzo de 1960 se establece un encuentro con directores de escuelas de comunicación e información para determinar el estado del campo (Ciespal, 1965, en León, 2012, p. 239) y para 1963-65 se dan ya encuentros regionales de capacitación para consolidar redes e indagar sobre la enseñanza del periodismo y el estado de los medios de información. Se destacan cuatro de ellos (León, 2012, Wettman, 1974): Medellín, México D.F., Buenos Aires y Brasil, que generaron 128 recomendaciones para las escuelas, con la puesta en cuestión del periodismo como ciencia independiente, así como del equilibrio entre formación humanista y profesional (Fernández, 1961), la homologación de saberes y la recopilación temática de inquietudes para fortalecer la comunicación.

Esto refleja que la acción de Ciespal con los cursos incidió fuertemente en la construcción alternativa para la comunicación (Meditsch, 1999), el concepto

12 La universidad central inició con las gestiones luego del seminario en Costa Rica de 1958 y envío como delegado a Luis Verdesoto Custode a la Conferencia General de Unesco en noviembre de 1958. Gracias a los apoyos del rector Alfredo Pérez Guerrero y de Jorge Salvador Lara por la misión diplomática, se pudo presentar la iniciativa ecuatoriana y lograr el consenso de la misma en esta conferencia. Luego de esto, se comparten los estatutos del Centro de Estrasburgo Ver: Mesa, 1984, pp. 86-88. 
de "profesional polivalente" (Marques de Melo) y la integración de reflexiones sobre la repercusión social de la comunicación. Ciespal apuesta además a recibir el "oleaje de las nuevas teorías de comunicación, fruto de los nuevos planteamientos de las ciencias sociales” (Proaño, 1984, p.2) y de manera puntual sostiene la formación del periodista fundamentada en análisis sociológicos y la reformulación del programa curricular. Para 1964, Ciespal ya había comenzado a desarrollar sus cursos con más de doscientos profesores y directores de escuelas (Meditsch, 1999). Estos resultados llegaron a ser conocidos rápidamente, y de quienes participaron "más del $85 \%$ de escuelas ya habían cambiado su denominación "de periodismo" por "de comunicación" o "equivalente" (Nixon, 1981, p.25), alcanzando un tercio de escuelas del continente que hicieron el cambio.

Las rutas de investigación se dinamizan con el primer perfil “morfológico y de contenido de los principales diarios de la región titulado «Dos semanas en la prensa de Latinoamérica» (CIESPAL)" (González, Rodríguez \& Aguaded, 2017, p. 433), que en 1962 revisó la producción mediática con análisis estadísticos sobre los factores de los diarios latinoamericanos en 1960, pionera en utilizar el análisis de contenido (Ayala, 2009) y que se convirtió en una metodología referente y comparativa durante el siguiente lustro ${ }^{13}$, seguido por estudios de uso de los medios en Argentina, Brasil, Ecuador, Colombia, Panamá, Perú y República Dominicana. De esta forma, comienza la inquietud para comparar las investigaciones, por lo que se impulsa en 1970 el Centro de Documentación para la Investigación de la Comunicación en América Latina. León (2014) indica la relevancia del proyecto conjunto con el Centro Internacional de Investigaciones para el Desarrollo (CIID) y la actividad de su jefe regional, Luis Ramiro Beltrán, así como con la Fundación Friedrich Ebert (1974), lo que permitirá contar con cierta sostenibilidad de estos procesos por dos décadas.

Pero, sin duda, Chasqui: Revista Latinoamericana de Comunicación se convirtió en la principal herramienta para la aglutinación de este talante latinoamericano y desde los países del "tercer mundo". Su primera época va de 1972 a 1978 con un marcado carácter de la producción y de la investigación en Ciespal que quería: un pensamiento periodístico-comunicacional de ALC, un estatuto epistemológico y la construcción de las ciencias sociales desde y para la región (Chasqui, 1972). Tuvo un total de "21 números, en los que se contabilizan 71 artículos y ensayos sobre las primeras investigaciones de la región” (González, Rodríguez \& Aguaded, 2017, p. 433), generando líneas para la creación los centros de enseñanza superior de periodismo.

Ciespal incrementa a la par la difusión de indagaciones relacionadas directamente al campo de la comunicación y recopila la producción existente. Merino-Utreras (1974) describe 773 trabajos, con 195 libros, 227 folletos y 311 artículos sobre comunicación para inicios de los setenta. En ella prioriza

13 Estudio de morfología y contenido en 429 ediciones distintas de 33 diarios, incluidos 4 en otros idiomas: The New York Times, The Times, Le Monde e Izvestia. Ver: https://ciespal.org/historia/ 
112 trabajos por ser investigaciones de laboratorio (63\%), de campo (35\%) y experimental (2\%). Su detalle nacional para varios países servirá como línea de base para los estudios de Beltrán sobre "las principales áreas de concentración temática, subraya las tendencias en cuanto a tópicos investigados” (González, Rodríguez \& Aguaded, 2017, p. 438).

A esta primera puesta en escena vino la respuesta de la teoría crítica dentro de los debates sobre la dependencia y los modelos de desarrollo en la región hacia finales de los años sesenta y principios de los setenta, con la exigencia "acerca de las especificidades históricas, sociales, políticas y culturales de la región" (Moyano, 2016, p. 13). Uno de los acontecimientos más importantes se dio con la investigación de la comunicación en ALC realizada por Ciespal, preludio para de la Declaración de Costa Rica en 1973. Entre otras cosas, se concluyó que "a falta de un marco conceptual propio para la investigación latinoamericana, se habría incurrido en la adopción, sin juicio crítico, de metodologías extrarregionales" (Ciespal, 1973). Gobbi (2008, en Moyano, 2016) indica que la dependencia provenía de seguir el modelo funcionalista y las teorías norteamericanas y Martín Barbero menciona que "se produjo un movimiento de "ruptura de la concepción hegemónica de la comunicación” enraizada en posiciones psicologistas y conductistas" (Moyano, 2016, p. 13). En su clausura se invitó a los investigadores a buscar "nuevas brechas teóricas y metodológicas para conseguir resultados aún más satisfactorios, compatibles con las necesidades de América Latina" (Marques de Melo, 2012, p. 13).

En particular emerge la agenda sobre las funciones activas del "Estado democrático" y "representativo de la comunidad de la Nación”, para la formulación, estimulación, ejecución y arbitraje de políticas nacionales de comunicación articuladas en nombre de la "colectividad nacional" y la “planificación para el desarrollo nacional” (Beltrán, 1976). Su debate se tomará en cuenta en 1976 dentro del Marco de Acción de Unesco con la petición para que ALC las aplique; se refuerzan también con la difusión del denominado Nuevo Orden Mundial de la Comunicación (NOMIC), que alcanzó su apogeo en los años posteriores a través del Informe McBride (Beltrán 1976; Gobbi, 2008; Moyano, 2016). De todas maneras, ya habían precedentes importantes como los de Pasquali e implicó la búsqueda de una comunicación ligada a "la resistencia contra las dictaduras militares en la región, (que) se tornó visible recién hacia finales de la década del setenta y principios de los ochenta, con el desarrollo de los estudios apuntalados" (Gobbi, 2008 en Moyano, 2019, p. 13). Las pesquisas de Ciespal abordaron cuestiones sobre la comunicación social, estructura social, incursionando en el campo de la propiedad de los medios de comunicación y sujeta al desarrollo político y filosófico de la época (Barrera, 1978, p.21) sobre las posibilidades de implementación de las propias políticas.

La ruptura con el paradigma funcionalista se da así por el rechazo a la imposición de los modelos de desarrollo (visibles en los programas de implementación de la época) que lideró la Comisión Económica para América 
Latina (Cepal), y por la propuesta de una comunicación antimperialista (como señala León, 2001) que acompañara una nueva forma de planificación e inserción en la modernización. Esta advertencia recuerda que "en este período histórico la comunicación y los medios de comunicación de masas alcanzaron el estatuto de "agentes insustituibles" para la consecución de dichos procesos de desarrollo e industrialización" (Moragas, 2011 en Moyano, 2016, p. 64) lo que significó un pensamiento profundo acerca de su uso dual: como determinadores de la explotación o como parte del ejericicio democrático (Mattelart \& Mattelart, 1995). Asimismo, el contacto con las teorías críticas será diverso, pues se da en varios niveles, desde la revisión de las formas de producción de la comunicación, su propiedad, distribución, hasta la reproducción ideológica y la construcción de la rutina informativa, y que se puede señalar principalmente por la influencia de:

la Escuela de Frankfurt, las teorías marxistas de la economía política, la antropología estructuralista de Lévi-Strauss, la semiología de Barthes. Y esta competencia de perspectivas teóricas sobre los procesos de Comunicación y sobre los procesos sociales en América Latina se vio reflejada en el debate de la primera mitad de los años setenta sobre las implicaciones políticas e ideológicas de las posiciones teóricas de los investigadores; debate que se localizó en el sur del continente, y que estuvo protagonizado, por un lado, por la corriente semiológica de la escuela estructuralista francesa, que se postuló como síntesis teórica entre psicoanálisis, marxismo y lingüística estructural, y, por otro lado, por la socioeconomía de inspiración marxista. (Moyano, 2016, p. 65)

Ciespal tuvo en este abordaje, de acuerdo a Custodia Da Silva, dos entradas: en la primera, se intentó impregnar en el subconsciente la idea primermundista, y en la segunda, comienza a trabajar en las teorías económicas y sociológicas de la región (Medina, 1999).

Por otro lado, la experiencia de Ciespal logra un impacto regional gracias a los programas de capacitación y becarios (la OEA había ofrecido becas desde su fundación que se reforzaron con otros programas como Radio Neederland Training Center, el apoyo de UNESCO, FES, Radio y el CIIDA en Canadá) (Proaño, 1984, p.3). Esta generación de comunicadores interactuó no solo con Ciespal sino con las redes, creando una dinámica en la aplicación de prácticas profesionales y las discusiones para la transformación de las prácticas comunicacionales, en las que se contempló la formación tanto de expertos como de otros participantes (muchos de ellos vinculados a movimientos sociales) en una rica interlocución de fuerzas del subcontinente (Idem, p.67). De igual modo, no debe olvidarse que desde 1974, cuando la Asamblea General de las Naciones Unidas propuso las reformas del nuevo orden de la información (1976), Ciespal ya había apuntalado una visión de capacitación comprometida (desde el manejo de los programas de televisión, cine, discos, hasta la producción de noticias) (Proaño, 1984, p.3), para "fomentar el perfeccionamiento profesional en la región" (Medina, 1999, p.67) 
e intercambiar nuevas perspectivas académicas en las instituciones y carreras de comunicación.

Ciespal era considerado para entonces "como el centro más importante para la promoción del intercambio de noticias de televisión en América Latina” (Wettman, 1999, p. 25). Se establece la alianza del Programa Internacional para el Desarrollo de la Comunicación (PIDC, 1980), que impulsa la denominada comunicación para el desarrollo, lo que coincide con la Conferencia General de UNESCOylos principios que sostenían estos consensos:igualdad socialy cultural; libertad de prensa y de información; y respeto por la identidad cultural; como parte de una política orientada a modificar la situación de los medios (Chasqui, 1980; Moyano, 2016). Profesionales, académicos y funcionarios, formaron parte de las nuevas generaciones de estudiantes, particularmente luego de la reunión de 1979 con directores de escuelas y facultades de comunicación sobre lo que serían los siguientes años y el área de planificación en la comunicación y la educación e investigación en comunicación para esta década (Prieto, 2009).

Un punto que se debe profundizar es el papel que cumple Ciespal en la institucionalización de la comunicación en ALC. Como se indicó, con el surgimiento de Alaic en 1978 y de Felafacs en 1981, la agenda de la comunicación comienza a contar con un circuito especializado de investigación e intercambio en diferentes congresos, revistas y documentos, además de configurar una comunidad epistémica al interno de las facultades de comunicación para homologar sus mallas. Para Orozco (1997) y Marques de Melo, Alaic será la red institucional que tome la posta en los ochenta. Pero estos mismos autores (así como Moyano, Prieto, Beltrán) indican que la conformación de Alaic surge luego del encuentro impulsado por Ciespal en Costa Rica y que Ciespal es el actor fundante en esa tradición (León, 2012, p. 238), "la piedra angular en la construcción de la investigación académica de la Comunicación en América Latina durante el período" (Moyano, 2016, p. 21), "abriendo la vía para la institucionalización del subcampo de la investigación y, paralelamente, para la consolidación de los proceso de enseñanza" (León Duarte, 2006).

En 1981, se inicia la segunda época de Chasqui. Sus principales temas de debate enmarcan la democratización de las comunicaciones, la necesidad de contar con códigos de ética periodística, se discuten los conceptos de propaganda y contrapropaganda en la prensa obrera y sindical, entre otros. Los estudios permanecen a la vanguardia de la difusión de metodologías y técnicas en ALC. A su vez, el centro tuvo mayor impacto en docentes, escuelas de periodismo y facultades de comunicación, unidas a materias de investigación y planificación (Ayala, 2009, p. 46), sobre la formación académica de periodistas, “perfiles de comunicación”, estadísticas sobre los medios en América Latina y un diagnóstico de la comunicación social y el desarrollo integral en América Latina, con el que se da por concluida la década designada por la CEPAL como 'desarrollo difundido' (Ayala, 2009). Bajo la metodología de la Información, 
Educación y Comunicación (IEC), creada por las Naciones Unidas, se trabajaron temas sobre la salud y protección ambiental (Ayala, 2009).

Al finalizar los años ochenta y durante los noventa, Ciespal toma nuevos rumbos con estudios sobre los movimientos y participación de la sociedad civil, problemas que se engloban en la distribución de información, estudios fenomenológicos, ciencias del lenguaje, semiología, semántica y aproximaciones a la cultura y antropología de la comunicación (Medina, 1999). Erazo (2009) realza en las nuevas acciones de CIESPAL el Centro de Producción en Televisión, que retoma la formación especializada en producción audiovisual y televisiva, lenguaje televisivo, televisión digital, nuevos formatos narrativos para TV, protagonismo social en el manejo informativo, entre otros (Herrera, 2009). Dentro de los grandes cambios para la nueva década, se encuentran la producción comunicativa "hacia usos tecnológicos y macrosociológicos de la información” (Serrano, 2009, p. 28). Se explora una línea de géneros periodísticos y metodologías para el rol de los medios en ALC que incluye los desafíos de la era digital, la globalización y nuevos formatos, la comunicación en internet, así como las nuevas políticas para esta expansión.

En la primera década del S. XX, Ciespal busca un cariz de una comunicación inclusiva y abierta a todas las voces y movimientos en una esfera pública sólida que logre "democratizar la comunicación para democratizar la sociedad" (Checa, 2009, p. 15). También se dan ejercicios autorreflexivos del oficio periodístico en conjunción con los análisis académico-profesionales para mejorar su actividad (Checa, 2009). Las principales líneas de investigación y las más importantes que se trabajaron fueron: la comunicación como un derecho, narrativas mediáticas, tecnoculturas, género y minorías: la violencia simbólica y observación de medios con crítica mediática y puesta en marcha de un observatorio (Checa, 2016). Ciespal propició en esta época la recuperación de las propuestas de los autores más importantes de las escuelas latinoamericanas, a quienes se dedican números especiales y se invitan para la generación de seminarios y la constitución de cátedras y grupos de investigación especializados ${ }^{14}$.

\section{Conclusiones y puntos de debate}

Durante la investigación se ha observado la complejidad para la definición de las teorías y escuelas de comunicación latinoamericana. Esto se debe a su

14 Jesús Martin Barbero. Una agenda intercultural (2008). Núm. 102; Germán Castro Caycedo, La crónica: periodismo de largo aliento. (2008) Núm. 103; José Marqués de Melo: El vínculo entre la realidad y la academia (2008). Núm. 104; Luis Ramiro Beltrán. Investigación, políticas y comunicación para el desarrollo. (2009). Núm. 105; Néstor García Canclini. Culturay comunicación en la sociedad digital. (2009). Núm. 106; Pascual Serrano. Medios públicos (2009). Núm. 108; Antonio Pasquali. Libertad de expresión. (2010). Núm. 109; Los Mattelart. Critica y militancias de la comunicación. (2010). Núm. 110; Eliseo Verón. Radio y tendencias digitales. (2019). Núm. 111; Manuel Martín Serrano y sus aportes a la comunicación. (2011). Núm. 114-115; Alfonso Gumucio Dragon. Comunicación y desarrollo. (2011). Núm. 116. Para los años 2015-2017 las ediciones de Chasqui tienen un desarrollo temático interdisciplinario más ecléctico. 
surgimiento reciente en la concepción "moderna" en la que se ubica a partir de mediados del S. XX. Sin embargo, saltando este escollo, es importante que exista una periodización de su contexto originario en los debates con las escuelas de comunicación europeas y norteamericanas en su llegada y asimilación en la región de ALC y en la conceptualización de la comunicación precolombina (que paradójicamente es una de las que más tarda en comenzarse con Beltrán y el grupo de Ameribcom).

Así, las propuestas de Esteinou, Kaplún, Marques de Melo, Fuentes, Mattelart \& Mattelart, entre otros, coinciden en señalar que el conductismo, funcionalismo y difusionismo son las tendencias que más influyen para entonces. Allí se ubica el nacimiento de Ciespal, en 1959, que coincide con el momento de ebullición en ese movimiento para la consolidación del periodismo y la comunicación en la región. Esa es la principal debilidad y fortaleza que se expresa a lo largo de su primera década de trabajo, con un momento inicial deficitario del funcionalismo, la Escuela de Chicago y el conductismo que se intenta adaptar, pero que resalta su originalidad como institución pionera que concreta un proyecto de investigación y generación de metodologías, investigaciones, capacitaciones y acciones regionales.

No obstante, la capacidad de generación de pensamiento crítico dentro de las ciencias sociales en general y de la comunicación en particular en Latinoamérica, significó la creación de una conciencia para la fundamentación propia, y prontamente se atiende a las dificultades y vacíos de esta forma de comprensión. La llegada de pensamiento crítico en los ochenta y noventa genera una simbiosis con planteamientos de ALC que se conjugan para consolidar propuestas como los de centro-periferia, la liberación y soberanía, la superación de modelos impuestos de desarrollo, que se tradujeron en vertientes fundamentales para su aplicación en la comunicación, con los estudios sobre propiedad de los medios, la revisión de la industria cultural dominante, y con posteridad de la ideología y dominación mediática. La capacidad de Ciespal para dar pasos en esa dirección es significativa y marca otra área, ya que para algunos autores pareciera que esta evolución tardó demasiado y que quizás hubo reticencias al respecto. Una revisión de los proyectos de investigación en relación a los de cooperación, las redes e ideas dominantes y la cabida generada a otras tesis "más radicales, puede servir para el análisis de estas ideas. Otro aspecto que se puede explorar es el carácter geopolítico de la Guerra Fría y la influencia que tuvo en las distintas iniciativas, tanto institucionales, como de colaboración en proyectos, y consolidación de los instrumentos internacionales de UNESCO que se concretaron en los documentos que construyeron estos pasos iniciales (y que pueden seguirse en los casos de Informe MacBride, el Nuevo Orden Mundial, las Asambleas Regionales, entre otros).

En esta investigación, se ha optado por seguir la línea cronológica - temática para abordar la construcción del campo como sugieren Esteinou y Martín Barbero y así contrastar con las acciones de Ciespal en cada fase. Esto no 
significa que los otros abordajes no puedan servir para una reflexión similar que podría trabajarse en una mirada más orgánica en la construcción de cada uno de los sub-campos o escuelas. Sin embargo, sí permite revisar las escuelas generales y los modelos de comprensión latinoamericanos que siguiendo a Kaplún pasan del funcionalismo a la teoría crítica, las propuestas reflexivo/ alternativas, de estudios culturales y los decoloniales-interculturales, y en los cuales se mantienen vigentes y latentes las cuestiones sobre la apropiación, emancipación, liberación, consumo, recepción, mediación, resistencia y mutación cultural Martín Barbero, Marques de Melo, Beltrán).

De igual manera, la priorización de la propuesta institucional de la escuela latinoamericana, de la cual Ciespal es el miembro fundacional, por lo que es fundamental revisar su interacción con los grupos y redes asociados a esta visión. Será muy importante observar los proyectos conjuntos con las otras instituciones mencionadas en la literatura como Alaic y Felafacs, además de las nuevas redes regionales, sus dinámicas, objetivos y trabajo conjunto para la internacionalización y superación del "asilacionismo" y "síndrome colonizado". Esta entrada es muy sugerente para indagar también desde los estudios de construcción de un paradigma latinoamericano y sería un aporte para indicar el contexto y desafíos no solo de Ciespal, sino de las demás iniciativas de esta acción-red para la estructuración del conocimiento propio.

Este ejercicio puede ser muy importante para el objeto de estudio, pues se puede enfocar el estado de la escuela latinoamericana y la relación con Ciespal a partir del énfasis que se ha dado durante los últimos diez años a sus propuestas y autores emblemáticos. Así, por ejemplo, se puede revisar la construcción de la agenda de investigación de los números de Chasqui en este último periodo que retoman a varios de los autores originarios (Martín Barbero, Kaplún, Beltrán, Mattelart, Marques de Melo, entre otros), las temáticas (periodismo, comunicación comunitaria, metodologías críticas) y su relación con las cátedras de investigación y las líneas editoriales, para detallar las especificidades de actores y grupos vigentes ${ }^{15}$. Asimismo, una revisión bibliométrica desde esta perspectiva será fundamental para conocer no solamente índices, sino intercambios y conocimiento-reconocimiento de las experiencias.

Estas perspectivas posibilitan una comparación con el camino ya recorrido por la escuela latinoamericana y Ciespal, a la vez que actualiza las referencias documentales, la generación y aplicación de metodologías, el desarrollo curricular para los centros de periodismo y de comunicación de la región y la capacitación especializada. Estos rasgos seguirán hacia adelante y son vigentes, resaltando el legado de "un centro de estudios que desde su fundación contribuyó

15 Entre otros: de estudios culturales (Martín Barbero, Omar Rincón, Nilda Jacks, Marroquín); críticos (Efendy Maldonado, Mattelart); análisis del discurso (Iván Rodrigo); comunicación comunitaria (Erick Torrico, Mauro Cerbino, Gissela Dávila, Cecilia Khroling); economía política (Bolaños, Follari) y comunicación alternativa (Aler, Alai, Amar); comunicación para el cambio social (Alfonso Gumucio, Sandra Massoni); educomunicación y comunicación popular (Daniel Prieto Castillo, Carlos Cortés). 
a enriquecer el pensamiento de critico de América Latina y la capacitación de 20.000 personas comunicación, interacción de 33 países del continente, es un acontecimiento que habla por sí solo" (Steingler, 2004, p.17).

Es importante esta experiencia en función de los cambios teóricos en las prácticas sociales, los aportes a la consolidación institucional de la propuesta desde ALC, el monitoreo mediático, las formas innovadoras de la comunicación y su relación con las democracias y movimientos sociales y ciudadanos. De igual manera, se espera seguir las derivas hacia la consecución de un equilibrio de la perspectiva de investigación-acción y diálogo de saberes, que evite un elitismo intelectual ajeno a los desafíos regionales y la generación continua de formas de entendimiento ancladas al territorio y los pueblos de Nuestra América.

\section{Referencias bibliográficas}

Beltrán, L. R., Herrera M, K., Pinto, E. \& Torrico, E. (2008). La comunicación antes de Colón. Tipos y formas en Mesoamérica y los Andes. Bolivia: Centro Interdisciplinario de Estudios de la Comunicación (CIBEC).

Bolaño, C. (2012). Comunicación y la Crítica de la Economía Política perspectivas teóricas y epistemológicas. Quito: CIESPAL.

Castellanos, V. (1997). Historia de las teorías de la comunicación (reseña). Revista Mexicana de Ciencias Políticas y Sociales. Vol 41. Núm. 169. Doi: http://dx.doi.org/10.22201/ fcpys.24.484.92xe.1997.169.4.9344

Castillo, A, Almansa, M. \& Álvarez, N. (s/f). Investigación latinoamericana en comunicación. Estudio bibliométrico de revistas científicas. Revista latinoamericana de ciencias de la comunicación. En: https://www.alaic.org/revista/index.php/alaic/issue/view/17/

Castillo, A. \& Álvarez, A. (2015). Autores en revistas latinoamericana de mayor impacto de comunicación. Opción, vol. 31, núm. 3. pp. 70-9o.

Chaparro, M. (2015). Claves para repensar los medios y el mundo que habitamos. La distopía del desarrollo. Bogotá: Ediciones desde abajo.

Chasqui (ed.). (1973). Seminario sobre la investigación de la Comunicación en América Latina. Chasqui. Revista Latinoamericana de Comunicación. Núm 4. oct-dic. pp. 11-25. Disponible en: https://revistachasqui.org/index.php/chasqui/article/view/2358/2356

Mesa, M. (1984). Orígenes históricos de Ciespal. Chasqui. Revista Latinoamericana de Comunicación. Núm 11. pp. 84-89. Disponible en: https://revistachasqui.org/index.php/chasqui/ article/view/175.5

Ciespal (ed.).(1999). 40 años de CIESPAL. Quito: Ciespal.

Esteinou, J. (1984). CIESPAL y la formación de imaginarios de la comunicación en América Latina. Chasqui. Revista Latinoamericana de Comunicación. Núm 11.jul-sep. pp. 20-28. Doi: 10.16921/chasqui.voil1.1747

Fernández, J. (1961). La formación de periodistas en América Latina. París: UNESCO.

Ferreira, L. (2000). Los códices y la ley de expresión precolombina. Diálogos de la comunicación. Núm. 58, pp. 80-93. FELAFACS. Disponible en: http://dialogosfelafacs.net/ wp-content/uploads/2012/01/58-revista-dialogos-los-codices-y-la-ley-de-expresion-precolombina.pdf

Fuentes, R. (1999). “La investigación de la comunicación en América Latina: condiciones y perspectivas para el siglo XXI.” Comunicación y Sociedad, 36 (2), pp.105-132. 
Gumucio, L.A. (2010). La comunicación antes de Colón. Archipiélago. Revista cultural de América Latina. Vol 18, No 68. pp. 50-51. Disponible en: http://www.revistas.unam.mx/ index.php/archipielago/article/view/24397

Gutiérrez, E. \& Cramer, G. (2019). Conversaciones con Clío: un campo, muchas historias. Rev. Palabra Clave. Historia(s) de la comunicación. Vol 22. núm. 4 pp. 1013-1018. Doi: 10.5294/pacla.2019.22.4.1

Hallo, W. (1992). Síntesis histórica de la comunicación y el periodismo en el Ecuador. Quito: Ediciones Bajo un Mismo Sol.

Kaplún, M. (1985). El comunicador popular. Quito: Ciespal

Kaplún, G. (2013). Viejas y nuevas tradiciones en la comunicación latinoamericana. Revista Latinoamericana de Ciencias de la Comunicación. Vol. 10, Núm. 18. pp. 66-76. Disponible en: https://www.alaic.org/revista/index.php/alaic/article/download/389/218

León- Duarte, G. (2017). José Marques de Melo y la construcción narrativa de la Escuela Latinoamericana de la Comunicación. Vol. 11, Núm. 1. ISSN: 1517-7-7606

Lopes de Vasallo, M. (2012). La investigación de la comunicación: cuestiones epistemológicas, teóricas y metodológicas. Revista Diálogos de la comunicación. Núm. 74. FELAFACS. Disponible en: www.dialogosfelafacs.net/wp-content/uploads/2012/01/74-revista-dialogos-la-investigacion-de-la-comunicacion.pdf

Maldonado, E. (2010). Michèle y Armand Mattelart pensadores, investigadores, militantes y fundadores de la investigación y las teorías críticas en comunicación en América Latina. Chasqui. Revista Latinoamericana de Comunicación. Núm. 110. Jun. pp.4-7. DOI: https:// doi.org/10.16921/chasqui.voi110.655 . (2015). Epistemología de la comunicación. Análisis de la vertiente Mattelart en América Latina. Quito: Ediciones Ciespal.

Marques de Melo, J. (1987). Teoría e investigación de la comunicación en América Latina. balance preliminar de los últimos 25 años. Estudios sobre las Culturas Contemporáneas, I (2). pp. 53-72. Disponible en: https://www.redalyc.org/articulo.oa?id=316/31610203 . (2009). Pensamiento comunicacional latinoamericano. Entre el saber y el poder. Sevilla: Ed. Comunicación Social. http://humanae.esuda.com.br/index.php/ humanae/article/download/552/180

Mattelart, A. \& Mattelart, M. (2003). Historia de las teorías de la comunicación. Barcelona: Paidós.

Moura, M (2009). Jesús Martín-Barbero: las formas mestizas de los medios. Pesquisa. FAPEP. Núm. 163. Sept. Disponible en: https://revistapesquisa.fapesp.br/es/200g/og/o1/lasformas-mestizas-de-los-medios/

Orozco, G. (1997). La investigación de la comunicación dentro y fuera de América Latina. Tendencias, Perspectivas y Desafíos del Estudio de los Medios. La Plata: Ediciones UNLP.

Prieto, D. (1985) Apuntes sobre comunicación popular educativa. Quito: Ciespal.

Roncallo, S., Uribe, E. \& Goyeneche, E. (2016). Volver a los clásicos. Teorías de la comunicación y cultura pop. Bogotá: Universidad de La Sabana. Uniediciones.

Russi, P. (2010). Por los caminos de Armand y Michèle Mattelart. Provocaciones y aportes para estudiar la comunicación. Chasqui. Revista Latinoamericana de Comunicación. Núm. 110, jun. pp.4-7. DOI: https://doi.org/10.16921/chasqui.voi110.665

Valencia R., J. (2011). Mediaciones, comunicación y colonialidad: encuentros y desencuentros de los estudios culturales y la comunicación en Latinoamérica. Signo y Pensamiento. Núm. 6o. Vol. XXX, Ene-Jun. pp 156 - 165. 


\section{Referencias bibliográficas (1): rol de CIESPAL y la teoría latinoamericana ${ }^{16}$}

Álvarez, A. \& Castillo, A. (2015). Autores en revistas latinoamericana de mayor impacto de comunicación. Opción. Vol. 31, Núm. 3. pp. 70-90. Disponible en: https://www.redalyc. org $/ \mathrm{pdf} / 310 / 31045567005 . \mathrm{pdf}$

Checa-Montúfar, F. (2016). La investigación de la comunicación en CIESPAL 2009 - 2014. Razón y Palabra. 20 (93), pp. 48-65. ISSN: 1605-4806. Disponible en: https://www. redalyc.org/articulo.oa?id=1995/199545660004

Fuentes, R. (2014). La investigación de la comunicación en América Latina: una nacionalización desintegrada. Disponible en: http://sedici.unlp.edu.ar/bitstream/handle/10915/44875/Documento completo.pdf? sequence $=1 \&$ isAllowed $=\mathrm{y}$

. (2016). Cuatro décadas de internacionalización académica en el campo de estudios de la comunicación en América Latina. Anuario Electrónico de Estudios en Comunicación Social Disertaciones. 9 (2). pp. 8-26. Doi: http://dx.doi.org/10.12804/disertaciones.09.02.2016.01

González, H., Romero, L. \& Aguaded, I. (2017). La investigación en comunicación en Latinoamérica: Una aproximación histórica. Historia y comunicación social. Vol. 22.2, pp. 427-443.

Hurtado, E. (2005). “Lo que pasó en Ciespal”. Apuntes etnográficos sobre el poder, los medios y los sin-sentidos de la violencia. Íconos. Revista de Ciencias Sociales. Num. 23, Sep. pp. 63-82. DOI: https://doi.org/10.17141/iconos.23.2005.123

León, G. (2002). Teorías e Investigación de la Comunicación en América Latina. Situación Actual. pp. 19-47. Ámbitos. Núm. 7-8. $2^{\circ} 2001$ - 1er 2002. pp. 19-47.

. (2012). Historia y Comunicación en América Latina: El papel de Ciespal en el proceso de institucionalización de los estudios de la Comunicación en América Latina. MHCJ. Núm. 3. Dic. Disponible en: https://mhcommunicationsjournal.wordpress. com/2012/12/og/gustavo leon/

. (2017). José Marques De Melo y la Construcción Narrativa de la Escuela Latinoamericana de la Comunicación. Revista Hum@nae. Vol. 11, núm. 1. ISSN: 1517-7606.

Marques de Melo, J. \& Gobbi, M. (2000). Gênese do pensamento comunicacional latino-americano: o protagonismo das instituições pioneiras- CIESPAL, ICINFORM, ININCO. São Paulo: UNESCO - UMESP. III CELACOM.

. (2004). Los tiempos Heroicos: La formación de la comunidad latinoamericana de Ciencias de la Comunicación. Texto presentado en la Sección de Historia de la Conferencia Mundial de Ciencias de la Comunicación, promovida por la International Association for Media and Communication Research - IAMCR, en la ciudadde Porto Alegre, Brasil. ALAIC. Disponible en: https://www.alaic.org/revista/ index.php/alaic/article/viewFile/110/108

Martin-Barbero, J. (2014) Pensar la comunicación en Latinoamérica. Revista Redes.com. 10. pp.21-39. doi: 10.15213/redes.

Meditsch, E. (1991). Adiós Ciespal: Ruptura brasileña en la enseñaza del periodismo. Comunicación y Sociedad. Núm. 13. sep-dic. pp. 11-23. Disponible en: https://www.academia. edu/35348521/Adi\%C3\%B3s_CIESPAL_Ruptura_brasile\%C3\%B1a_en_la_ense $\% \mathrm{C} 3 \%$ -

16 Se enlistan las referencias de los artículos seleccionados, ya que por la extensión del cuadro analítico utilizado para la investigación no puede ser anexado con todas sus categorías y que se espera publicar más adelante. 
B1anza_del_periodismo_1991

Mellardo, C. (2010). La influencia de CIESPAL en la formación del periodista latinoamericano. Una revisión crítica. Estudios sobre el Mensaje Periodístico. Núm 16. pp.307318. Disponible en: https://revistas.ucm.es/index.php/ESMP/article/viewFile/ESMP1010110307A/1144.3

Moyano, R. (2016). Procesos de estructuración de las prácticas teórico-metodológicas de la investigación académica de la comunicación en América Latina. ALAIC y FELAFACS (2000-2010). Tesis doctoral. Disponible en: http://sedici.unlp.edu.ar/handle/10915/57209 . (2018). La investigación académica de la comunicación en América Latina desde la perspectiva de los sistemas complejos. Chasqui. Revista Latinoamericana de Comunicación. pp. 299-321. Disponible en: https://revistachasqui.org/index.php/chasqui/ article/view/3043

Pineda de Alcázar, M. (2001). Las teorías clásicas de la comunicación: Balance de sus aportes y limitaciones a la luz del siglo XXI. Opción. Año 17. Núm. 36. pp.11-29. Disponible en: https://dialnet.unirioja.es/descarga/articulo/24755.96.pdf

Sphera Publica (2007). La investigación de la comunicación en Iberoamérica: historia, estado actual y nuevos retos. Sphera Pública. Número extraordinario. Disponible en: https:// dialnet.unirioja.es/ejemplar/207387

\section{Referencias bibliográficas (2): Textos referidos en Chasqui. Revista Latinoamericana de Comunicación}

Ayala, A. (2009). 50 años de investigaciones aplicadas. Chasqui. Revista Latinoamericana de Comunicación. Núm. 107, pp. 44-47. Disponible en: https://revistachasqui.org/index. php/chasqui/article/view/1533

Beltrán, L. R. (1973). Comunicación y desarrollo económico. Chasqui. Revista Latinoamericana de Comunicación. Núm. 2, pp. 50-72. Disponible: https://revistachasqui.org/index. php/chasqui/article/view/2345

. (1995). Salud pública y comunicación social. Chasqui. Revista Latinoamericana de Comunicación. Núm. 51, pp. 33-37. Doi: https://doi.org/10.16921/chasqui.voi51.2260 . (1996). La radio popular y educativa en América Latina. Chasqui. Revista Latinoamericana de Comunicación. Núm. 53, pp.8-11. DOI: https://doi.org/10.16921/chasqui.voi53

. (1998). ¿De malos amigos a ángeles guardianes? Chasqui. Revista Latinoamericana de Comunicación. Núm. 64. Disponible en: https://revistachasqui.org/index. php/chasqui/article/view/1240

. (2000). El sueño en la nevera. El sueño en la nevera. Chasqui, Revista Latinoamericana de Comunicación. Núm. 7o. Disponible en: https://revistachasqui.org/index. $\mathrm{php} /$ chasqui/article/view/1350

. (2007). La investigación de la comunicación, ayer y hoy. Temas y objetivos de investigación en la comunicación de ayer. Chasqui. Revista Latinoamericana de Comunicación. Núm. 100, pp.16-21. Disponible en: https://revistachasqui.org/index.php/chasqui/ article/view/353

. (2008). Entre el poder y el saber: Recuento del pensamiento latinoamericano. Chasqui. Revista Latinoamericana de Comunicación. Núm. 104, pp. 26-31. Disponible en: https://revistachasqui.org/index.php/chasqui/article/view/336 
. (2011). El promotor internacional de la comunicación para el cambio social. Revista Latinoamericana de Comunicación. Núm. 116, pp. 12-16. Disponible en: https:// revistachasqui.org/index.php/chasqui/article/view/106

Canclini, N. (1983). Las políticas Culturales en América Latina. Chasqui. Revista Latinoamericana de Comunicación. Núm. 7, pp. 18-26. Disponible en: https://revistachasqui.org/ index.php/chasqui/article/view/1734

Checa-Montufar, F. (1999). Carta del Editor. Chasqui. Revista Latinoamericana de Comunicación. Núm. 64. DOI: https://doi.org/10.16921/chasqui.voi67.1299

Erazo, E. (2009). CIESPAL: origen de una institución integradora. Chasqui. Revista Latinoamericana de Comunicación. Núm. 11, pp. 4-7. Disponible en:https://revistachasqui.org/ index.php/chasqui/article/view/1525

Esteinou, J. (1984). CIESPAL y la formación de imaginarios de la comunicación en América Latina. Chasqui. Revista Latinoamericana de Comunicación. Núm. 11,pp. 20-28. doi: 10.16921/chasqui.voi11.1747

Espinoza, H. (2009). La radio en el proyecto comunicacional del CIESPAL. Chasqui. Revista Latinoamericana de Comunicación. Núm. 11, pp. 38-41. Disponible en: https://revistachasqui.org/index.php/chasqui/article/view/1531

Fuenzalida, V. (1988). Modelos de recepción de mensajes. Chasqui. Revista Latinoamericana de Comunicación. Núm. 27. Disponible: https://revistachasqui.org/index.php/chasqui/ article/view/1917

. (1992). La ética cotidiana de la teleficción. Chasqui. Revista Latinoamericana de Comunicación. Núm. 41, pp. 22-24. Disponible en: https://revistachasqui.org/index. php/chasqui/article/view/733

. (1993). TV broadcasting para el desarrollo. Chasqui. Revista Latinoamericana de Comunicación. Núm. 45, pp. 94-100. Disponible en: https://revistachasqui.org/index. $\mathrm{php} / \mathrm{chasqui} /$ article/view/724.

. (1995). Motivaciones infantiles ante la TV. Chasqui. Revista Latinoamericana de Comunicación, Núm. 53, pp. 51-54. Disponible: https://revistachasqui.org/index.php/ chasqui/article/view/1006

. (1996). Violencia y TV infantil. Chasqui. Revista Latinoamericana de Comunicación. Núm. 53, pp. 51-54. Disponible: https://revistachasqui.org/index.php/chasqui/ article/view/1006

. (1997). La cultura en televisión Nacional de Chile. Chasqui. Revista Latinoamericana de Comunicación. Núm. 59, pp.57-61. Disponible en: https://revistachasqui. org/index.php/chasqui/article/view/590

. (1998). Hacia la reforma de la TV Pública. Chasqui. Revista Latinoamericana de Comunicación. Núm. 64. Disponible en: https://revistachasqui.org/index.php/ chasqui/article/view/1251

. (2006). Los niños y la televisión. Chasqui. Revista Latinoamericana de Comunicación. Núm. 93, pp. 40-45. DOI: https://doi.org/10.16921/chasqui.voi.93.219

. (2009). Televisión Nacional de Chile. El reto digital propone una nueva normativa. Chasqui. Revista Latinoamericana de Comunicación. Núm. 108, pp. 17-23. Disponible: https://revistachasqui.org/index.php/chasqui/article/view/168

Herrera, C. (2009). La televisión en el CIESPAL. Chasqui. Revista Latinoamericana de Comunicación. Núm. 107, pp. 42-43. Disponible en: https://revistachasqui.org/index.php/ chasqui/article/view/1532 
Kaplún, M. (1978). Cassette - Foro. Un sistema de comunicación participatoria. Chasqui. Revista Latinoamericana de Comunicación. Núm. 20, pp. 29-42. Disponible en: https:// revistachasqui.org/index.php/chasqui/article/view/2433

. (1982). Panel. Uso de los medios masivos en los procesos educativos. Chasqui. Revista Latinoamericana de Comunicación. Núm. 5, pp. 4-13. DOI: https://doi.org/10.16921/chasqui.voi5.2805 . (1983). La Comunicación Popular ¿Alternativa válida? Chasqui. Revista Latinoamericana de Comunicación. Núm. 7, pp.18-26. Disponible: https://revistachasqui.org/ index.php/chasqui/article/view/1736

. (1993). Rius para principiantes, recepción Chasqui. Revista Latinoamericana de Comunicación. Núm. 45, pp.61-64. Disponible en: https://revistachasqui.org/index. php/chasqui/article/view/716

. (1997). De medios y fines en comunicación educativa. Chasqui. Revista Latinoamericana de Comunicación. Núm. 58. Disponible en: https://revistachasqui.org/index. php/chasqui/article/view/1120

. (1998). Procesos educativos y canales de comunicación. Chasqui. Revista Latinoamericana de Comunicación. Núm. 64. Disponible en: https://revistachasqui.org/ index.php/chasqui/article/view/1235

Lofredo, G. (1989). La Agenda hasta el 2000. Chasqui. Revista Latinoamericana de Comunicación. Doi: https://doi.org/10.16921/chasqui.voi32

Marques de Melo, J. (1984). La investigación latinoamericana en comunicación. Chasqui. Revista Latinoamericana de Comunicación. Núm. 11, pp.12-19. DOI: https://doi. org/10.16921/chasqui.voin1.1745

. (2007). La investigación de la comunicación, ayer y hoy. Reto de la investigación latinoamericana en comunicación. Chasqui. Revista Latinoamericana de Comunicación, Núm. 100, pp.8-13. Disponible en: https://revistachasqui.org/index. $\mathrm{php} /$ chasqui/article/view/351

. (2008). Telenovela: Folletín de mis des/reecuentros. Revista Latinoamericana de Comunicación. Núm. 104, pp.40-45. Disponible en: https://revistachasqui. org/index.php/chasqui/article/view/338

. (2009). Resgate do pensamento latino-americano. Desafio inadiável do campo da comunicaçao. Chasqui. Revista Latinoamericana de Comunicación. Núm. 107, pp.8-13. Disponible en: https://revistachasqui.org/index.php/chasqui/article/view/1526

Martin-Barbero, J. (1985). Sentido de una reforme curricular. Chasqui. Revista Latinoamericana de Comunicación. Núm. 13, pp. 62-74. Disponible: https://revistachasqui.org/ index.php/chasqui/article/view/1782

. (1986). ¿Re-intelección de los medios? Apuntes acerca del libro de los Mattelart. Chasqui. Revista Latinoamericana de Comunicación. Núm. 20, pp.17-20. DOI: https://doi.org/10.16921/chasqui.voi20.1854.

. (2015). ¿Desde dónde pensamos la comunicación hoy? Chasqui. Revista Latinoamericana de Comunicación. Núm. 128, pp.13-29. Disponible en: https://revistachasqui.org/index.php/chasqui/article/view/2545

Mattelart, A., Mattelart, M. (1987). Trucos para escribir bien - Entrevista. Entrevista a Michelle y Armand Mattelart. Chasqui. Revista Latinoamericana de Comunicación. Núm. 24, pp. 8-11. Disponible en: https://revistachasqui.org/index.php/chasqui/article/view/835 . (2011). Comunicación y movimiento popular. Un momento emblemático. Chile 1970-1973 Chasqui. Revista Latinoamericana de Comunicación. 116, pp. 
75-80. Disponible: https://revistachasqui.org/index.php/chasqui/article/view/134

Medistch, E. (1999). CIESPAL: progreso y problema del comunicólogo. Chasqui. Revista Latinoamericana de Comunicación. Núm. 67. Disponible en: https://revistachasqui.org/ index.php/chasqui/article/view/1317/1346

Pasquali- García, A. (1983). ¿Contradicción entre libertad y equilibrio informativo? Chasqui. Revista Latinoamericana de Comunicación. Núm. 8, pp.26-31. Disponible: https:// revistachasqui.org/index.php/chasqui/article/view/931

. (1996) El reordenamiento del mundo. Revista Latinoamericana de Comunicación. Núm. 44, pp.21-25. DIsponible en: https://revistachasqui.org/index. php/chasqui/article/view/2117

. (1993) Venezuela: La tentación cesarista: entre la debilidad y la violencia. Revista Latinoamericana de Comunicación. Núm. 45, pp.68-73. Disponible en: https:// revistachasqui.org/index.php/chasqui/article/view/718

. (1993). Vértigo compacto. Chasqui. Revista Latinoamericana de Comunicación. Núm.46, pp. 68-71. Disponible en: https://revistachasqui.org/index.php/chasqui/ article/view/673

. Comunicación ¿̇para cuál desarrollo? Chasqui. Revista Latinoamericana de Comunicación. Núm. 53, pp.12-15. Doi: https://doi.org/10.16921/chasqui.voi53.995 . (2001). ¿Libertad de prensa o libertad de Empresa? Chasqui. Revista Latinoamericana de Comunicación. Núm. 75. Disponible en: https://revistachasqui.org/ index.php/chasqui/article/view/1405

. (2007). Dos apostillas a la libertad de expresión. Chasqui. Revista Latinoamericana de Comunicación. Núm. 100, pp.14-15. Disponible en: https://revistachasqui. org/index.php/chasqui/article/view/352

Peña, J., C. (2009). El CIESPAL cambió para bien mi visión profesional. Chasqui. Revista Latinoamericana de Comunicación. Núm. 107, pp. 48-51. Disponible en: https://revistachasqui.org/index.php/chasqui/article/view/1534.

Prieto-Castillo, D. (1982). Educación: Tecnologías y futuros. Chasqui. Revista Latinoamericana de Comunicación. Núm. 5, pp.65-72. Disponible en:https://revistachasqui.org/ index.php/chasqui/article/view/1711

. (1985). Controversia. Formación del comunicador y nuevas tecnologías. Chasqui. Revista Latinoamericana de Comunicación, Núm. 13, pp.44-51. Disponible en: https://revistachasqui.org/index.php/chasqui/article/view/1780

. (1985). Reflexiones sobe la tele duración universitaria. Chasqui. Revista Latinoamericana de Comunicación. Núm. 14, pp.80-82. Disponible en: https://revistachasqui.org/index.php/chasqui/article/view/1794

. (1987). Controversia. Tensión epistemológica y función social de la semiótica. Entre el denuncismo y el preciosismo. Chasqui. Revista Latinoamericana de Comunicación. Núm. 15, pp.31-43. Disponible en: https://revistachasqui.org/index.phpview/1801 . (1986). Bolivia: Comunicadores en idiomas nativos. Chasqui. Revista Latinoamericana de Comunicación. Núm. 18, pp.54-56. Disponible en: https://revistachasqui. org/index.php/chasqui/article/view/869

. (1987). Entrevista a Federeico Iglesias. Chasqui. Revista Latinoamericana de Comunicación. Núm. 21, pp.20-21. Disponible en: https://revistachasqui.org/index. php/chasqui/article/view/3033

. (1993). ¿Qué significa aprender? Chasqui. Revista Latinoamericana de Comunicación, Núm. 47pp.4-10. Disponible en:https://revistachasqui.org/index.php/ 
chasqui/article/view/2138. Núm. 47.pp. 4-10. Disponible en: https://revistachasqui.org/ index.php/chasqui/article/view/2138

. (1997). Educar y comunicar para la diferencia. Chasqui. Revista Latinoamericana de Comunicación. Núm. 6o. Disponible en: https://revistachasqui.org/index. php/chasqui/article/view/1159

. (1999). La experiencia del CIESPAL en los años 90: promoción y acompañamiento de aprendizajes en comunicación social. Chasqui. Revista Latinoamericana de Comunicación. Núm. 67, pp.32-37. Disponible en: https://revistachasqui.org/index. php/chasqui/article/view/1318 . (2004). Lectura crítica de Videomatch. Chasqui. Revista Latinoamericana de Comunicación. Núm. 85, pp.14-19. Disponible en: https://revistachasqui.org/index. php/chasqui/article/view/41.9 . (2007). El derecho a la comunicación. Chasqui. Revista Latinoamericana de Comunicación. Núm. 100 pp.16-21. Disponible en: https://revistachasqui.org/index. php/chasqui/article/view/353

. (2007). Sobre el periodismo, la ética y la democracia. Chasqui. Revista Latinoamericana de Comunicación. Núm. 99, pp.4-9. Disponible en: https://revistachasqui.org/index.php/chasqui/article/view/369

. (2009). CIESPAL: promoción y acompañamiento de aprendizajes en comunicación social. Chasqui. Revista Latinoamericana de Comunicación. Núm. 107, pp.32-37. Disponible en: https://revistachasqui.org/index.php/chasqui/article/view/1530 . (2017). Construirse para educar. Caminos de la educomunicación. Chasqui. Revista Latinoamericana de Comunicación. Núm. 135, pp.17-32. Disponible en: https:// revistachasqui.org/index.php/chasqui/article/view/3328

Proaño, E. (1984). Editorial: 25 años de CIESPAL. Chasqui. Revista Latinoamericana de Comunicación. Núm. 11, pp. 4-11. doi: https://doi.org/10.16921/chasqui.voin1

Quiroz, T. (2009). CIESPAL y los latinoamericanos. Chasqui. Revista Latinoamericana de Comunicación. Núm. 107, pp. 22-23. Disponible en: https://revistachasqui.org/index. php/chasqui/article/view/1528

Utreras-Merino, J. 1974). La investigación científica de la comunicación en Latinoamérica. Chasqui. Revista Latinoamericana de Comunicación. Núm. 5. pp. 81-103. Disponible en: https://revistachasqui.org/index.php/chasqui/article/view/2365/2363 
